\title{
Physicochemical Properties of Poly- $\gamma$-glutamic Acid Produced by a Novel Bacillus subtilis HA Isolated from Cheonggukjang
}

\author{
Ji-Hyun Seo ${ }^{1}$, Chan-Shick Kim ${ }^{2}$, and Sam-Pin Lee $^{3 \dagger}$ \\ ${ }^{1}$ The Center for Traditional Microorganism Resources (TMR), Keimyung University, Daegu 704-701, Korea \\ ${ }^{2}$ Faculty of Biotechnology, College of Applied Life Sciences, Cheju National University, Jeju 690-756, Korea \\ ${ }^{3}$ Department of Food Science and Technology, Keimyung University, Daegu 704-701, Korea
}

\begin{abstract}
A novel bacterium isolated from Cheonggukjang was identified as a glutamate-dependent Bacillus subtilis HA with $98.3 \%$ similarity to Bacillus subtilis Z99104. Optimization of poly- $\gamma$-glutamic acid ( $\gamma$-PGA) production by modulating fermentation factors including carbon sources, nitrogen sources, inorganic salts and fermentation time was investigated. Optimum culture broth for $\gamma$-PGA production consisted of $3 \%$ glutamate, $3 \%$ glucose and various salts, resulting in the PGA production of $22.5 \mathrm{~g} / \mathrm{L}$ by shaking culture for $72 \mathrm{hr}$ at $37^{\circ} \mathrm{C}$. Average molecular weight of $\gamma$-PGA was determined to be 1,220 kDa through MALLS analysis. The $\gamma$-PGA solution showed a typical pseudoplastic flow behavior, and a great decrease in consistency below pH 6.0 regardless of the same molecular weight of $\gamma$-PGA. The molecular weights of isolated $\gamma$-PGA were drastically decreased by heat treatment in various acidic conditions, resulting in different hydrolysis of $\gamma$-PGA. The consistency of $\gamma$-PGA solution was greatly decreased with increase heating time in acidic conditions.
\end{abstract}

Key words: Bacillus subtilis, poly- $\gamma$-glutamic acid, consistency index, molecular weight

\section{INTRODUCTION}

Poly- $\gamma$-glutamic acid $(\gamma$-PGA) is generally produced by bacteria of the Bacillus genus (1). It is an anionic homo-polyamide made of $\mathrm{d}$ - and l-glutamic acid units connected by amide linkages between $\alpha$-amino and $\gamma$ carboxylic acid groups (2). Therefore, the $\gamma$-PGA polymer is structurally and fundamentally different from proteins (3). $\gamma$-PGA is water-soluble, biodegradable, edible as well as non-toxic to humans and the environment. $\gamma$-PGA and its derivatives offer a wide range of unique applications. It has been used as a drug carrier $(4,5)$, curable biological adhesive $(6,7)$, biodegradable fibers (8), and highly water absorbable hydrogels (9).

Many researchers have tried to clarify the metabolic pathway and the enzymes related to $\gamma$-PGA synthesis and polymerization so as to enhance the productivity. Several $\gamma$-PGA producing Bacillus strains have been isolated from highly salty seasoning of fermented soybean foods $(10,11)$. Several Bacillus sp. produce $\gamma$-PGA as a viscous material or a capsular component. These strains are most useful in terms of industrial applications and have been studied most intensively. In order to enhance the $\gamma$-PGA productivity, several investigations of the nutrient requirements for $\gamma$-PGA production have revealed that the requirements varied according to the strain used (1).
According to the nutrient requirements, $\gamma$-PGA producing bacteria can be divided into two groups; one that requires the addition of l-glutamic acid in the medium to stimulate $\gamma$-PGA production, one that does not require l-glutamic acid. The $\gamma$-PGA as viscous material has particular viscoelastic properties. Its production is dependent upon the type of microorganisms and environmental factors such as temperature and nutrient composition $(1,12)$.

$\gamma$-PGA is a high molecular-weight polypeptide consisting of $\gamma$-linked glutamic acid units and its $\alpha$-carboxylic acid side chains can be chemically modified for a drug delivery carrier (13). For the production of $\gamma$-PGAcisplatin conjugate with anti-tumor effects, the average molecular weight of $\gamma$-PGA was reduced by heating after $\mathrm{HCl}$ treatment (14). $\gamma$-PGA is unique homo-biopolymer with various applications in food and medicinal field so that the characterization of its physicochemical properties will allow us to provide useful information for future research and applications.

The present study was carried out to optimize higher production of $\gamma$-PGA by a novel B. subtilis HA isolated from traditional fermented soybean food, characterize its physicochemical properties and modulate the molecular weight of $\gamma$-PGA. 


\section{MATERIALS AND METHODS}

\section{Materials and reagents}

All chemicals were purchased from Sigma Chemical (St. Louis, MO, USA) unless otherwise indicated. Glutamate was purchased from the Yakuri Pure Chemicals Co., Ltd. (Kyoto, Japan). BCA protein assay kit was purchased from the Bio-Rad (Hercules, CA, USA). Nutrient and MRS broth were purchased from the Difco (Detroit, MI, USA).

\section{Isolation of $\boldsymbol{\gamma}$-PGA producing Bacillus sp.}

The $\gamma$-PGA producing Bacillus strain was isolated from the traditional fermented soybean food, Cheonggukjang, through serial dilution and inoculated on MRS agar plate and incubated at $37^{\circ} \mathrm{C}$ for $24 \mathrm{hr}$. The Bacillus strain producing mucilage can be easily distinguished on MRS agar plates, since it grows with a sticky and rough morphology (15). The mucilage producing strains were isolated bacteria. To isolate a bacterial strain producing $\gamma$-PGA efficiently, the Bacillus strain isolated was cultured and then transferred to the defined media for $\gamma$ -PGA production. After incubation at $37^{\circ} \mathrm{C}$ for $24 \mathrm{hr}$, the strains producing viscous mucilage were selected and analyzed further. The defined medium for $\gamma$-PGA production was $2 \%$ glucose, $2 \%$ glutamate, $0.05 \% \mathrm{~K}_{2} \mathrm{HPO}_{4}$, $0.05 \%\left(\mathrm{NH}_{4}\right)_{2} \mathrm{SO}_{4}, \mathrm{MgSO}_{4} \cdot 7 \mathrm{H}_{2} \mathrm{O}, 0.01 \% \mathrm{CaCl}_{2}$ and 50 $\mu \mathrm{g}$ biotin according to the modified method of Goto and Kunioka (16). For solid medium $1.5 \%$ agar was added.

\section{Identification of $\boldsymbol{\gamma}$-PGA producing bacterium}

For $16 \mathrm{~S}$ rDNA sequencing the DNA from bacteria producing high mucilage isolated pure culture was prepared with Wizard $^{\circledR}$ genomic DNA purification kit (Promega, USA) according to the procedure recommended by the manufacturer. The universal primer used to amplify bacterial 16s rDNA were NS1 (5'-GTAG TCATATGCTTGTCTC-3') and NS8 (5'-TCCGCAGG TTCACCTACGGA-3'). The 16s rDNA products were purified using the Wizard $^{\circledR}$ SV Gel and PCR clean-up system (Promega, USA). The purified PCR products were analyzed using an ABI PRISM 3700 DNA Analyzer. DNA sequencing was performed by the Korean Culture Center of Microorganism (KCCM), Korea. DNA sequences sharing $99 \%$ identity with known sequences were assigned to the phylotype at Bacillus subtilis. It was assigned and deposited in the Korean Culture Center of Microorganism as KCCM 10775P. Sequences of insets were compared to the ribosomal DNA sequence in GenBank using BLAST program. Multiple alignments were performed with the Clustal X and Mega 2 program (17).

\section{Microorganisms and culture conditions}

Bacillus subtilis HA was used in this experiment. To prepare the starter culture $B$. subtilis HA was grown on MRS agar plate at $37^{\circ} \mathrm{C}$ for $24 \mathrm{hr}$, and then transferred to a $500 \mathrm{~mL}$ flask containing $150 \mathrm{~mL}$ of nutrient broth. The medium was cultured in a shaking incubator (SI-900R, Jeio Tech Co., Ltd., Korea) at $180 \mathrm{rpm}$ and $37^{\circ} \mathrm{C}$ for $24 \mathrm{hr}$.

Optimization of $\gamma$-PGA production by B. subtilis HA

To optimize the $\gamma$-PGA production, carbon and nitrogen sources were investigated. The optimum medium for $\gamma$-PGA production consists of $1 \mathrm{~g} \mathrm{Na}_{2} \mathrm{HPO}_{4}, 1 \mathrm{~g}$ $\mathrm{KH}_{2} \mathrm{PO}_{4}, 5 \mathrm{~g}\left(\mathrm{NH}_{4}\right)_{2} \mathrm{SO}_{4}, 0.5 \mathrm{~g} \mathrm{MgSO}_{4} \cdot 7 \mathrm{H}_{2} \mathrm{O}, 0.02 \mathrm{~g}$ $\mathrm{MnSO}_{4} \cdot 5 \mathrm{H}_{2} \mathrm{O}, 0.2 \mathrm{~g} \mathrm{CaCl}_{2} \cdot 2 \mathrm{H}_{2} \mathrm{O}, 30 \mathrm{~g}$ glutamate, and $30 \mathrm{~g}$ glucose in 1 liter distilled water according to the modified method of Goto and Kunioka (16). 3\% (v/v) of starter culture was inoculated into $500 \mathrm{~mL}$ Erlenmeyer flask containing $100 \mathrm{~mL}$ medium incubated at $37^{\circ} \mathrm{C}$ on a rotary shaker at $170 \mathrm{rpm}$ for $72 \mathrm{hr}$.

\section{Isolation and purification of $\gamma$-PGA}

The $\gamma$-PGA was purified by the modified purification method of Choi and Lee (18). For the purification of $\gamma$-PGA from B. subtilis HA, cells were harvested from the culture broth by centrifugation at $24,900 \times g$ for 10 min. Three volume of ethanol were added to culture supernatant mixed well and then centrifuged $(24,900 \times g$, $10 \mathrm{~min}, 4^{\circ} \mathrm{C}$ ). Precipitated materials (crude $\gamma$-PGA) were harvested and dried in a vacuum drying oven (VO-200, Sunil Eyela Co., Ltd., Korea) at $50^{\circ} \mathrm{C}(16)$. The precipitate was dissolved in distilled water. It was adjusted to $\mathrm{pH} 2.0$ by adding $6 \mathrm{~N} \mathrm{HCl}$ and left overnight at $4^{\circ} \mathrm{C}$. Then the supernatant was obtained after centrifugation and adjusted to $\mathrm{pH} 6.5$ with $6 \mathrm{~N} \mathrm{NaOH}$. Three volumes of ethanol were added to the supernatant, and the mixtures were mixed well and then centrifuged $(24,900 \times g$, $10 \mathrm{~min}, 4^{\circ} \mathrm{C}$ ). The resultant precipitate was collected by centrifugation at $24,900 \times \mathrm{g}$ for $10 \mathrm{~min}$ and then dissolved in distilled water. The $\gamma$-PGA solution was dialyzed in de-ionized water and then lyophilized.

\section{Analysis of purified $\gamma$-PGA}

Protein content remaining in the purified PGA was determined by the dye binding method of Bradford (19). Total sugar content was determined by the modified phenol/sulfuric acid method (20). A $1 \mathrm{~mL}$ of purified $\gamma$-PGA solution was mixed with $25 \mu \mathrm{L}$ phenol reagent $(80 \%$, $\mathrm{v} / \mathrm{v}$ ), and then added with $2.5 \mathrm{~mL}$ of concentrated sulfuric acid rapidly to the solution surface without allowing it to touch the sides of the tube. The solution was undisturbed for $10 \mathrm{~min}$ before shaking vigorously, and then determined the absorbance at $485 \mathrm{~nm}$. The intensity of 
the orange color is proportional to the amount of total carbohydrates present. The standard curve for calculating total carbohydrate was constructed with glucose as a standard sugar.

\section{Molecular weight analysis of $\boldsymbol{\gamma}$-PGA}

To determine the average molecular weight of $\gamma$-PGA the purified $\gamma$-PGA and its hydrolysate were dissolved in distilled water and filtered through a $0.45 \mu \mathrm{m}$ microfilter membrane prior to injection into the size exclusion chromatograph coupled with a multi angle laser light scattering system (21). The molecular weight range for light scattering is determined by the size of the dissolved polymer molecules without standard curve and using the refractive indices of solvent and polymer. A HPSEC system equipped with a multi-angle laser-light scattering detector (DAWN EOS; Wyatt Technology, SantaBabara, CA, USA) and refractive index detector (Optilab rEX; Wyatt Technology, SantaBabara, CA, USA) was used to determine the weight-average molecular weights of the $\gamma$-PGA and its hydrolysate. Shodex OHpak SB-805 column was used with a flow rate $1 \mathrm{~mL} / \mathrm{min}$, and the mobile phase was distilled water containing $0.1 \mathrm{M}$ $\mathrm{NaNO}_{3}$.

The concentration and molecular weight of $\gamma$-PGA were also measured using an Autochro-GPC system (Young In Scientific Co., Seoul, Korea) equipped with a Waters 410 Refractometer (Milford, MA) and a Shodex OHpak SB 800 HQ series column (SB 802.5, SB 805). The freeze-dried sample was suspended in $\mathrm{dH}_{2} \mathrm{O}$. The eluant containing $0.1 \mathrm{M} \mathrm{Na}_{2} \mathrm{SO}_{4}, 0.05 \%(\mathrm{w} / \mathrm{v})$ $\mathrm{NaN}_{3}$ was brought to $\mathrm{pH} 4.0$ using glacial acetic acid, and the flow rate was set at $1.0 \mathrm{~mL} / \mathrm{min}$ (22). The molecular weight and amount of $\gamma$-PGA was calculated using the peak area of the GPC measurements with purified $\gamma$-PGA as a standard.

\section{Physical properties of $\gamma$-PGA}

Rheological properties of the viscous culture broth and $\gamma$-PGA solution $(1 \sim 3 \%, \mathrm{w} / \mathrm{v})$ were determined using a Rheometer System (HAAKE RheoStress 1, Germany) equipped with a cone plate device (Platte PP35 Ti, 3.5 $\mathrm{cm}$ diameter, $\left.2^{\circ}\right)$. The flow behavior was determined by the shear rate $(1 \sim 100 / \mathrm{sec})$ at $20^{\circ} \mathrm{C}$, and consistency index $\left(\mathrm{Pa} \cdot \mathrm{sec}^{\mathrm{n}}\right)$ and flow behavior index were evaluated by the power-law model (23).

\section{Modulation of the molecular weight according to the} $\mathrm{pH}$, acids and heat-treatment

Changes in consistency index and molecular weight of $\gamma$-PGA $(1 \%, \mathrm{w} / \mathrm{v})$ according to heat and acid treatment with $\mathrm{HCl}$, citric acid and acetic acid were determined. The $\mathrm{pH}$ of $\gamma$-PGA was adjusted to $\mathrm{pH} 2,3,4,5,6$, and 7 with $6 \mathrm{~N} \mathrm{HCl}$ and $6 \mathrm{~N} \mathrm{NaOH}$ then followed by heat-treatment at $100^{\circ} \mathrm{C}$ for $60 \mathrm{~min}$ for $\mathrm{HCl}$. pH 2 was maintained for acetic acid and citric acid with heat-treatment at $100^{\circ} \mathrm{C}$ for $20 \mathrm{~min}$. The consistency index and molecular weight of the $\gamma$-PGA solution were measured periodically $(5 \sim 60 \mathrm{~min})$.

\section{Statistical analysis}

All the data were statistically analyzed by Student's $t$-test, and $p<0.05$ was considered to be statistically significant. Data were analyzed using SPSS ${ }^{\mathrm{TM}}$ version 12.0 for Windows (SPSS Inc., Chicago, IL), and the results were expressed as mean \pm standard deviation (SD)

\section{RESULTS AND DISCUSSION}

\section{Characterization of the $\gamma$-PGA producing strain}

The morphology of the newly isolated bacterium was rod-shape $(0.7 \sim 0.8 \mu \mathrm{m}$ length and $1.38 \sim 1.41 \mu \mathrm{m}$ breadth) as determined by scanning electron microscopic analysis. The strain grew well on MRS agar plate at 37 $42^{\circ} \mathrm{C}$, while no growth was observed at $25^{\circ} \mathrm{C}$ and $60^{\circ} \mathrm{C}$. The strain was able to perform starch and casein hydrolysis, gelatin liquefaction, nitrate reduction and catalase test, but negatively reacted to citrate utilization and oxidase test. The strain could grow in nutrient broth with $7 \% \mathrm{NaCl}$ but the growth was inhibited at $9 \% \mathrm{NaCl}$. From 16s rDNA partial sequencing, the strain belonged to the genus $B$. subtilis and was designated as Bacillus subtilis HA. B. subtilis HA was found to be closely related to B. subtilis Z99104 with $98.3 \%$ similarity.

\section{Optimization of medium for $\boldsymbol{\gamma}$-PGA production}

Modified medium of Goto and Kunioka (16) was used initially for the production of $\gamma$-PGA. It was found that B. subtilis HA produce optimum $\gamma$-PGA through submerged fermentation at $72 \mathrm{hr}$ with optimum temperature $37^{\circ} \mathrm{C}$. On the other hand, it was reported that the optimum production of $\gamma$-PGA from B. subtilis TAM4 and $B$. licheniformis was observed at $30^{\circ} \mathrm{C}(24,25)$.

To optimize the culture medium for $\gamma$-PGA production, tests of the effects of various carbon and nitrogen sources, magnesium and manganese were conducted. To determine the best carbon source for the $\gamma$-PGA production by $B$. subtilis HA, six different carbon sources were separately provided with $30 \mathrm{~g} / \mathrm{L}$ concentration. The $B$. subtilis HA grew well in media supplemented with maltose, glycerol, or mannose as a carbon source, but those carbon sources had little effect on the $\gamma$-PGA production. Among the carbon sources tested, glucose yielded the highest $\gamma$-PGA production $(11.1 \mathrm{~g} / \mathrm{L})$ (Fig. 1). The maximum $\gamma$-PGA production was obtained with 30 $\mathrm{g} / \mathrm{L}$ of glucose (Table 1). 


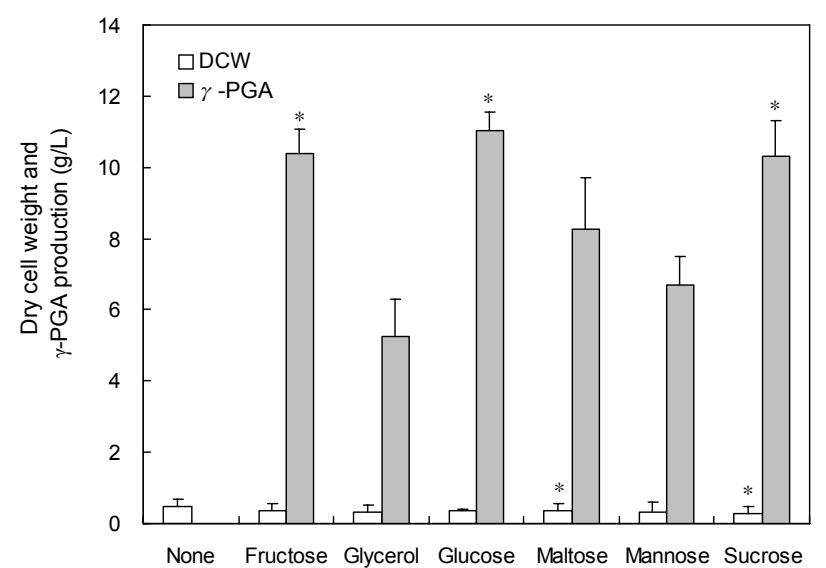

Fig. 1. Effect of various carbon sources on dry cell weight and $\gamma$-PGA production in shake-flask cultures of B. subtilis HA. All carbon sources were added to $30 \mathrm{~g} / \mathrm{L}$. The culture was incubated at $37^{\circ} \mathrm{C}$ on a rotary shaker at $170 \mathrm{rpm}$ for $48 \mathrm{hr}$ using the modified medium of Goto and Kunioka (16). DCW: dry cell weight. Data shown are mean $\pm S D$ values. A value with an asterisk is significantly different from the control group by $t$-test $\left({ }^{*} \mathrm{p}<0.05\right)$.

Table 1. Effects of glucose, ammonium sulfate, magnesium sulfate, manganese sulfate and calcium chloride concentrations on the $\gamma$-PGA production in shake-flask culture of $B$. subtilis HA

\begin{tabular}{|c|c|c|c|}
\hline Sources & $\begin{array}{l}\text { Concentration } \\
(\mathrm{g} / \mathrm{L})\end{array}$ & $\begin{array}{c}\gamma \text {-PGA production } \\
(\mathrm{g} / \mathrm{L})\end{array}$ & $\begin{array}{l}\text { Cell growth } \\
(\mathrm{g} / \mathrm{L})\end{array}$ \\
\hline \multirow{6}{*}{ Glucose } & 0 & - & $0.39 \pm 0.05$ \\
\hline & 10 & $7.92 \pm 0.63$ & $0.48 \pm 0.05$ \\
\hline & 20 & $9.61 \pm 0.48$ & $0.54 \pm 0.03$ \\
\hline & 30 & $11.05 \pm 0.51$ & $0.46 \pm 0.03$ \\
\hline & 40 & $9.34 \pm 0.60$ & $0.43 \pm 0.05$ \\
\hline & 50 & $8.69 \pm 1.50$ & $0.43 \pm 0.05$ \\
\hline \multirow{4}{*}{$\begin{array}{l}\text { Ammonium } \\
\text { sulfate }\end{array}$} & 0 & $0.97 \pm 0.15$ & $0.56 \pm 0.66$ \\
\hline & 5 & $11.05 \pm 0.51$ & $0.32 \pm 0.03$ \\
\hline & 10 & $10.55 \pm 0.05$ & $0.32 \pm 0.01$ \\
\hline & 15 & $10.54 \pm 0.25$ & $0.45 \pm 0.01$ \\
\hline \multirow{7}{*}{$\begin{array}{l}\text { Magnesium } \\
\text { sulfate }\end{array}$} & 0 & - & $0.12 \pm 0.00$ \\
\hline & 0.5 & $11.05 \pm 0.51$ & $0.26 \pm 0.03$ \\
\hline & 1.0 & $10.02 \pm 0.26$ & $0.31 \pm 0.01$ \\
\hline & 1.5 & $9.62 \pm 0.50$ & $0.27 \pm 0.03$ \\
\hline & 2.0 & $9.42 \pm 0.40$ & $0.19 \pm 0.01$ \\
\hline & 2.5 & $9.05 \pm 0.14$ & $0.18 \pm 0.00$ \\
\hline & 3.0 & $8.01 \pm 0.38$ & $0.18 \pm 0.01$ \\
\hline \multirow{6}{*}{$\begin{array}{l}\text { Manganese } \\
\text { sulfate }\end{array}$} & 0 & $11.04 \pm 1.00$ & $0.20 \pm 0.07$ \\
\hline & 0.02 & $11.05 \pm 0.51$ & $0.32 \pm 0.03$ \\
\hline & 0.04 & $9.00 \pm 1.00$ & $0.35 \pm 0.08$ \\
\hline & 0.06 & $8.17 \pm 0.72$ & $0.30 \pm 0.01$ \\
\hline & 0.08 & $6.00 \pm 0.41$ & $0.29 \pm 0.02$ \\
\hline & 0.10 & $5.49 \pm 0.57$ & $0.28 \pm 0.07$ \\
\hline \multirow{5}{*}{$\begin{array}{l}\text { Calcium } \\
\text { chloride }\end{array}$} & 0 & $8.67 \pm 1.15$ & $0.23 \pm 0.08$ \\
\hline & 0.2 & $12.17 \pm 1.26$ & $0.26 \pm 0.06$ \\
\hline & 0.4 & $17.33 \pm 0.76$ & $0.27 \pm 0.07$ \\
\hline & 0.6 & $14.43 \pm 0.81$ & $0.23 \pm 0.06$ \\
\hline & 0.8 & $14.1 \pm 1.01$ & $0.23 \pm 0.06$ \\
\hline
\end{tabular}

Data shown are mean $\pm \mathrm{SD}$ values.
Various nitrogen sources like yeast extract, tryptone, beef extract, peptone, $\left(\mathrm{NH}_{4}\right)_{2} \mathrm{SO}_{4}, \mathrm{NH}_{4} \mathrm{Cl}$ were tested for $\gamma$-PGA production. Among the nitrogen sources tested, $\left(\mathrm{NH}_{4}\right)_{2} \mathrm{SO}_{4}$ yielded the highest $\gamma$-PGA production (Fig. 2). The maximum $\gamma$-PGA yield $(11.1 \mathrm{~g} / \mathrm{L})$ was obtained in defined medium supplemented with $5 \mathrm{~g} / \mathrm{L}$ of $\left(\mathrm{NH}_{4}\right)_{2} \mathrm{SO}_{4}$ as the nitrogen source (Table 1). $\mathrm{Mg}^{2+}$ and $\mathrm{Mn}^{2+}$ have been reported to significantly stimulate $\gamma$-PGA production by their addition to the medium $(25,26) . \gamma$-PGA was not produced without the addition of $\mathrm{Mg}^{2+}$ but addition of a small amount of $\mathrm{Mg}^{2+}$ resulted in the stimulation of $\gamma$-PGA production. The maximum production of $\gamma$-PGA was achieved with the addition of $0.5 \mathrm{~g} / \mathrm{L}$ of $\mathrm{MgSO}_{4} \cdot 7 \mathrm{H}_{2} \mathrm{O}$ to the medium. However, the amount of produced $\gamma$-PGA decreased proportionally to the amount of $\mathrm{Mn}^{2+}$ added to the medium. The results indicate that B. subtilis HA require $\mathrm{Mg}^{2+}$ but not $\mathrm{Mn}^{2+}$ for the production of $\gamma$-PGA. Production of $\gamma$-PGA also increased by adding $0.4 \mathrm{~g} / \mathrm{L}$ of $\mathrm{CaCl}_{2} \cdot 2 \mathrm{H}_{2} \mathrm{O}$ to the medium (Table 1). Thus, the addition of $\mathrm{CaCl}_{2} \cdot 2 \mathrm{H}_{2} \mathrm{O}$ increases $\gamma$-PGA production. From above results, the optimal composition of defined medium for production of $\gamma$-PGA was determined as below: $1 \mathrm{~g} \mathrm{Na}_{2} \mathrm{HPO}_{4}, 1 \mathrm{~g} \mathrm{KH}_{2} \mathrm{PO}_{4}, 5 \mathrm{~g}$ $\left(\mathrm{NH}_{4}\right)_{2} \mathrm{SO}_{4}, 0.5 \mathrm{~g} \mathrm{MgSO}_{4} \cdot 7 \mathrm{H}_{2} \mathrm{O}, 0.4 \mathrm{~g} \mathrm{CaCl}_{2} \cdot 2 \mathrm{H}_{2} \mathrm{O}, 30$ $\mathrm{g}$ glutamate, $30 \mathrm{~g}$ glucose and $500 \mu \mathrm{g}$ biotin per 1 liter culture broth.

$\gamma$-PGA production was evaluated in the defined medium with optimal nutrient composition as shown in Fig. 3 , the $\gamma$-PGA production and consistency index increased rapidly during the fermentation for $72 \mathrm{hr}$, showing a $\gamma$ -

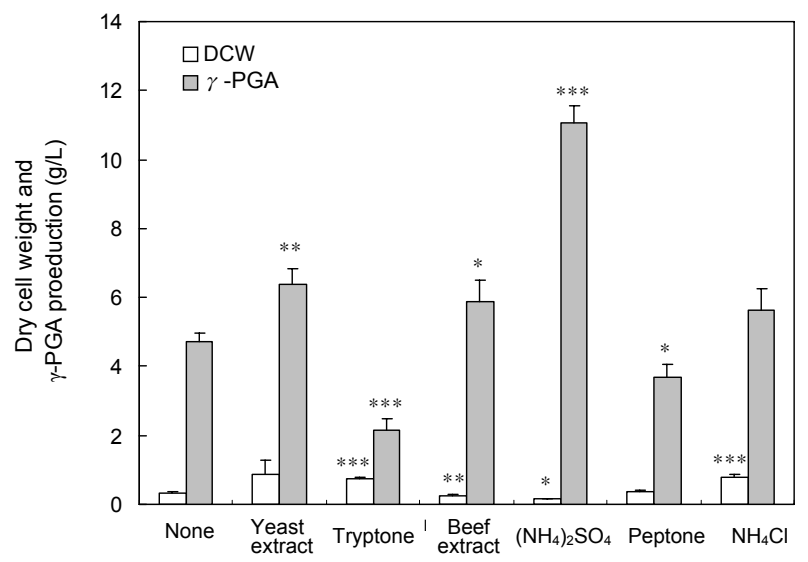

Fig. 2. Effect of various nitrogen sources on dry cell weight and $\gamma$-PGA production in shake-flask cultures of B. subtilis HA. All nitrogen sources were added to $5 \mathrm{~g} / \mathrm{L}$. The culture was incubated at $37^{\circ} \mathrm{C}$ on a rotary shaker at $170 \mathrm{rpm}$ for $48 \mathrm{hr}$ using the modified medium of Goto and Kunioka (16). DCW: dry cell weight. Data shown are mean \pm SD values. A value with an asterisk is significantly different from the control group by $t$-test $\left({ }^{*} \mathrm{p}<0.05,{ }^{* *} \mathrm{p}<0.01,{ }^{* * *} \mathrm{p}<0.001\right)$. 


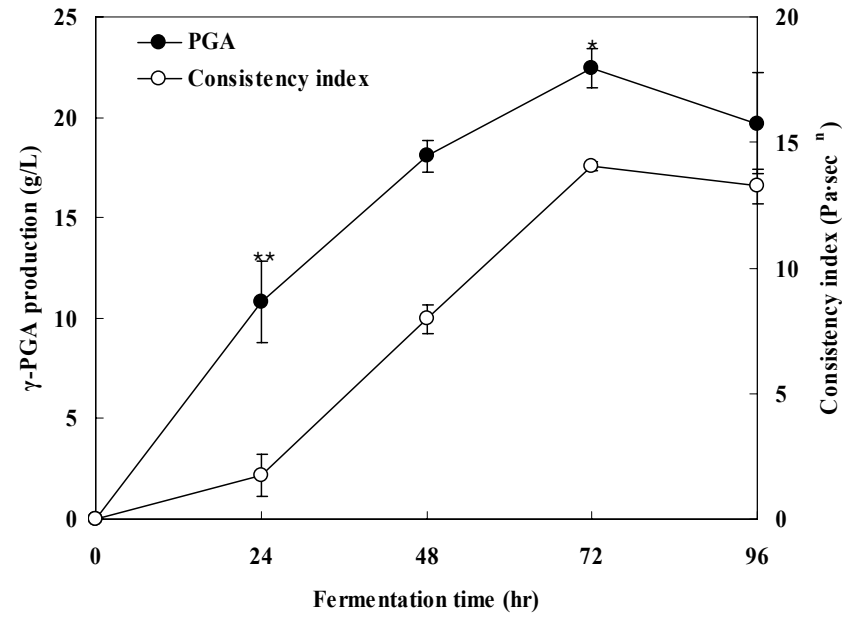

Fig. 3. Comparison of $\gamma$-PGA production and consistency index according to fermentation time in shake-flask cultures of B. subtilis HA. The culture was incubated at $37^{\circ} \mathrm{C}$ on a rotary shaker at $170 \mathrm{rpm}$. Data shown are mean $\pm \mathrm{SD}$ values. A value with an asterisk is significantly different from the control group by $t$-test $\left({ }^{*} \mathrm{p}<0.01,{ }^{* *} \mathrm{p}<0.001\right)$.

PGA production of $22.5 \mathrm{~g} / \mathrm{L}$. After then, $\gamma$-PGA production and consistency index decreased slightly. This may be due to the partial enzymatic hydrolysis of the $\gamma$-PGA in late stage of fermentation. Such a hypothesis was supported for natto mucilage, which was hydrolyzed by depolymerase produced by Bacillus sp., resulting in decreased viscosity (27). Considering that the utilization of glutamate in defined medium, B. subtilis HA could produce $22.5 \mathrm{~g} / \mathrm{L}$ of $\gamma$-PGA from $30 \mathrm{~g} / \mathrm{L}$ glutamate. Compared to previous reports about the $\gamma$-PGA yield $(3,28,29)$, the conversion of glutamate in optimized culture medium by $B$. subtilis $\mathrm{HA}$ is considered to be efficient.

\section{Physico-chemical properties of $\boldsymbol{\gamma}$-PGA}

The molecular weight and the ratio of carbohydrate to protein for purified $\gamma$-PGA were investigated. The molecular weight of purified $\gamma$-PGA was determined by GPC analysis. Purified $\gamma$-PGA as standards were used to construct a calibration curve, from which unknown molecular weights of $\gamma$-PGA were calculated (Fig. 4A). The molecular weight of purified $\gamma$-PGA was determined to be $1220 \mathrm{kDa}$. As shown in Fig. 4B, purified $\gamma$-PGA showed the retention time of $8.14 \mathrm{~min}$ in HPLC chromatogram. The purified $\gamma$-PGA consisted of approximately $96.9 \% \gamma$-PGA, $0.1 \%$ protein content and $3.0 \%$ total sugar (carbohydrate) content. It has been reported that the molecular weight of $\gamma$-PGA varies according to the culture conditions and strain types, ranging from 100 to $2,000 \mathrm{kDa}(30)$. The consistency index was sharply increased with increasing $\gamma$-PGA concentration as shown in Table 2. When the consistency index of $\gamma$-PGA (30
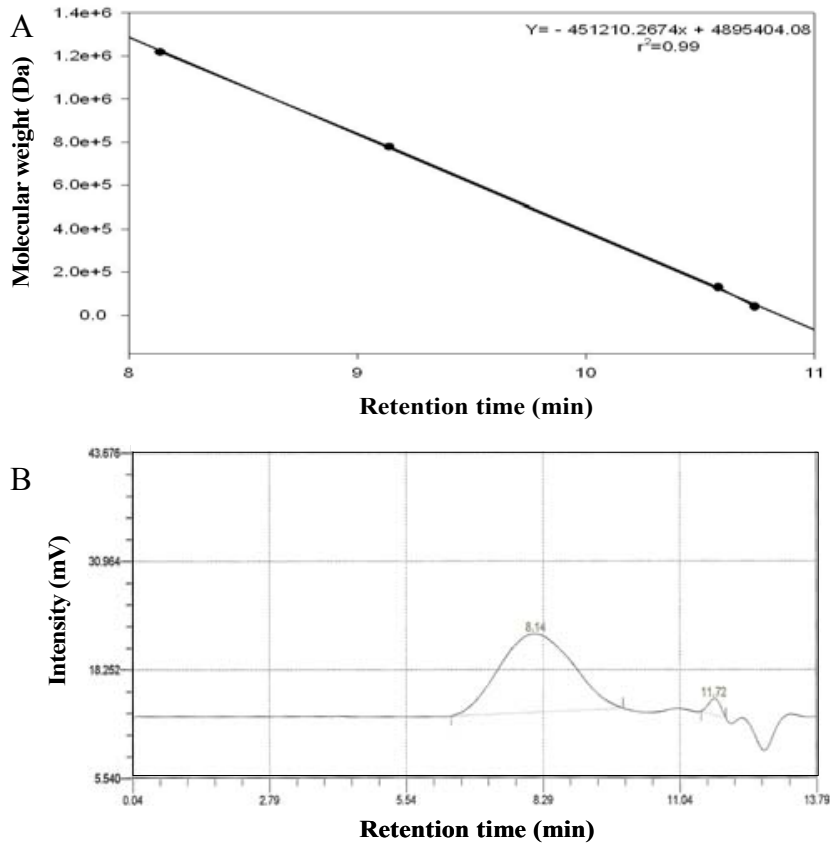

Fig. 4. Standard curve of molecular weight of $\gamma$-PGA and HPLC chromatogram of molecular weight of purified $\gamma$-PGA. A: Standard curve of molecular weight of $\gamma$-PGA by using GPC column. The molecular weight was determined by SEC-MALS. The molecular weight of $\gamma$-PGA was $1220 \mathrm{kDa}$, $243 \mathrm{kDa}, 63 \mathrm{kDa}$ and $24 \mathrm{kDa}$, respectively. B: $8.14 \min (\gamma-$ PGA), 11.72 min (by-product).

$\mathrm{g} / \mathrm{L})$ solution was compared with that of $\gamma$-PGA $(10 \mathrm{~g} / \mathrm{L})$ under $100 / \mathrm{sec}$ of shear rate, its value increased 4 fold. The rheological characteristics of $\gamma$-PGA solution revealed the typical pseudoplastic properties, showing the decrease in the flow behavior index with increasing $\gamma$ PGA concentration.

Changes in the molecular weight and consistency index of $\gamma$-PGA according to $\mathrm{pH}$, heat-treatment and acids

Changes in the molecular weight of $\gamma$-PGA in aqueous solution were investigated by heat treatment at $100^{\circ} \mathrm{C}$. Generally, $\gamma$-PGA is water soluble anionic polypeptides which undergo structural changes related to the degree of ionization of $\gamma$-carboxyl group of $\gamma$-PGA (31). In the heat treatment, the molecular weight of $\gamma$-PGA was drastically reduced by lowed the $\mathrm{pH}$ in acid conditions. In

Table 2. Consistency index and flow behavior index at various $\gamma$-PGA concentrations

\begin{tabular}{crc}
\hline$\gamma$-PGA $\begin{array}{c}\text { concentration } \\
(\mathrm{g} / \mathrm{L})\end{array}$ & \multicolumn{2}{c}{ Power law model $^{1)}$} \\
\cline { 2 - 3 } 10 & $\mathrm{~K}\left(\mathrm{~Pa} \cdot \mathrm{sec}^{\mathrm{n}}\right)$ & $\mathrm{n}$ \\
\hline 20 & $5.01 \pm 1.00$ & $0.42 \pm 0.01$ \\
30 & $10.93 \pm 0.75$ & $0.38 \pm 0.01$ \\
& $19.90 \pm 0.12$ & $0.34 \pm 0.03$ \\
\hline
\end{tabular}

${ }^{1)}$ Power law model, $\sigma=\mathrm{K} \cdot(\gamma)^{\mathrm{n}} ; \sigma$, shear stress $(\mathrm{Pa}) ; \dot{\gamma}$, shear-rate $(1 / \mathrm{sec})$; K, consistency index $\left(\mathrm{Pa} \cdot \mathrm{Sec}^{\mathrm{n}}\right)$; $\mathrm{n}$, flow behavior index (dimensionless). 
the case of heating at $100^{\circ} \mathrm{C}$ and $\mathrm{pH} 2.0$, the molecular weight of $\gamma$-PGA was rapidly reduced to $243 \mathrm{kDa}, 63$ $\mathrm{kDa}$ and $24 \mathrm{kDa}$ by increasing heating times to $20 \mathrm{~min}$, $40 \mathrm{~min}$ and $60 \mathrm{~min}$, respectively (Fig. 5A). On the other hand, the molecular weight of $\gamma$-PGA was gradually reduced by the heat treatment at $\mathrm{pH}$ 6.0. At $\mathrm{pH} 7.0$ the $\gamma$-PGA molecular weight remained constant even with heat-treatment (Fig. 5A). Thus, it is concluded that the molecular weight of $\gamma$-PGA can be modulated by adjusting $\mathrm{pH}$ in acidic conditions as well as heat treatment. The consistency of $\gamma$-PGA solution was greatly decreased by increasing heating time at $100^{\circ} \mathrm{C}$. Furthermore, the consistency decrease was greatly dependent upon the $\mathrm{pH}$ value in acidic conditions (Fig. 5B). It has been reported that the $\gamma$-PGA polymer with un-ionized acid posses a helical conformation, and the polymer with ionized salt behaves like in the random coil state (32). Thus, it implied that a helical conformation of $\gamma$-PGA polymer due to un-ionized carboxylic groups in acidic conditions resulted in the decrease in consistency.

To evaluate the effects of acid types on the reduction

(A)

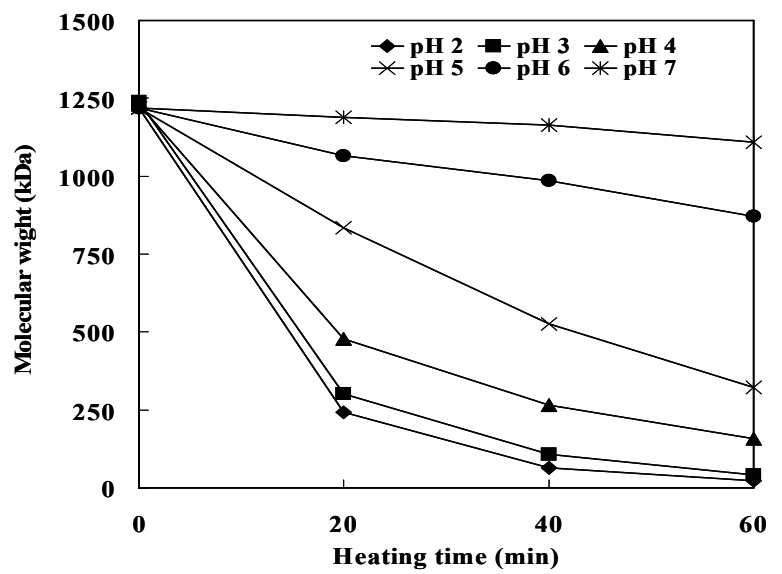

(B)

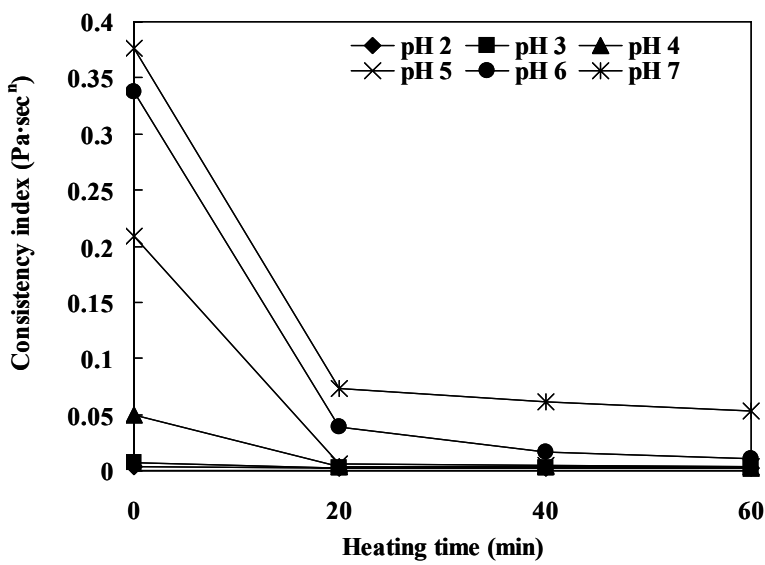

Fig. 5. Changes in molecular weight (A) and consistency index (B) of $\gamma$-PGA according to the heat-treatment at different $\mathrm{pH}$. $\gamma$-PGA solution, $1 \%(\mathrm{w} / \mathrm{v}) ; \mathrm{pH}$ control, $\mathrm{HCl}$ or $\mathrm{NaOH}$; heating temperature, $100^{\circ} \mathrm{C}$. of molecular weight of $\gamma$-PGA, citric acid and acetic acid as food ingredient were compared with hydrochloric acid. As shown in Fig. 6A, $\gamma$-PGA solution without heat treatment showed slightly different molecular weights in the case of the treatment with different acids. Among them acetic acid treatment showed a weak hydrolysis of $\gamma$-PGA compared with treatment of $\mathrm{HCl}$ or citric acid. This implies that $\gamma$-PGA in acid solution may be partially hydrolyzed. Furthermore, the heat treatment resulted in a drastic hydrolysis of $\gamma$-PGA. During heat treatment the hydrolytic degradation of $\gamma$-PGA in acetic acid solution was much weaker than that in $\mathrm{HCl}$ or citric acid. The molecular weight of $\gamma$-PGA solutions treated with $\mathrm{HCl}$, citric acid or acetic acid tended to decrease with increasing heating time (Fig. 6A). The molecular weight of $\gamma$ PGA with $1220 \mathrm{kDa}$ was gradually decreased to below $500 \mathrm{kDa}$ by heating for $20 \mathrm{~min}$. $\gamma$-PGA without heat treatment showed a different consistency index according to acid types used. The $\gamma$-PGA solution including acetic acid showed a higher initial consistency index compared to that of $\mathrm{HCl}$ or citric acid (Fig. 6B). In addi-

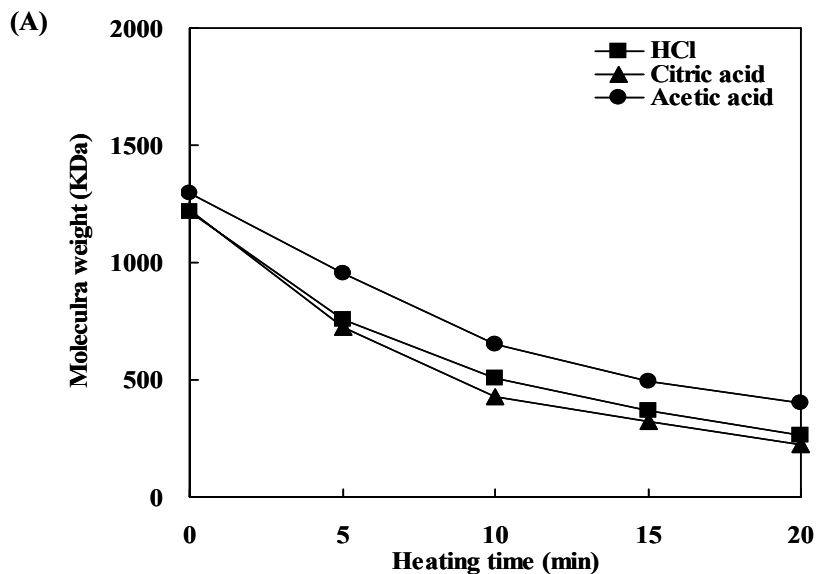

(B)

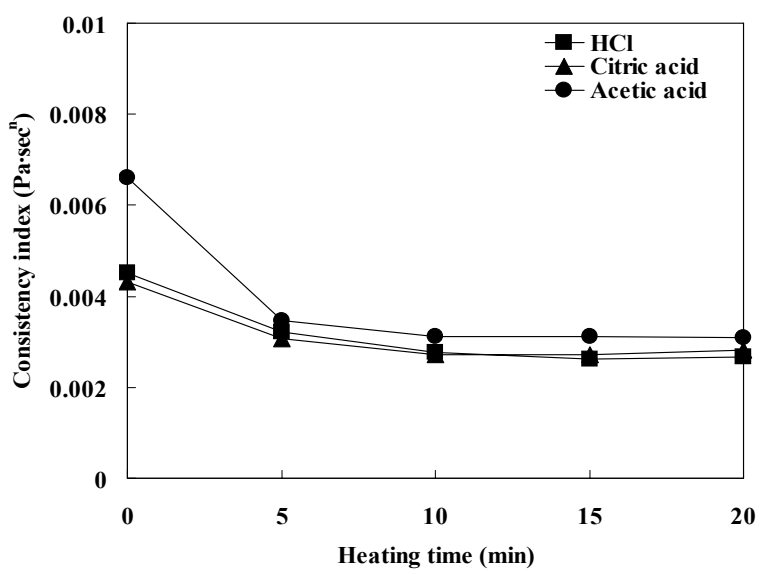

Fig. 6. Changes in molecular weight (A) and consistency index (B) of $\gamma$-PGA treated with different acids according to the heat-treatment. $\gamma$-PGA solution, $1 \%(\mathrm{w} / \mathrm{v})$; heating condition, $100^{\circ} \mathrm{C}(\mathrm{pH} 2.0)$. 
tion, the heat treatment for 5 min resulted in the rapid decrease in consistency index regardless of acid types. Thus, it is possible to make different molecular weight of $\gamma$-PGA in edible acetic acid through heat treatment or sterilization.

The molecular weight and consistency of $\gamma$-PGA are very important physicochemical properties, for manipulating the viscosity enhancement of fruit juice, beverages and sports drinks. It also promotes the absorption of minerals and food ingredients which enhance biologically active properties such as drug carrier or sustained release materials. From the above results, the consistency and molecular weight of $\gamma$-PGA produced by B. subtilis HA were able to be controlled by changing $\mathrm{pH}$ in acidic conditions, and applying different organic acids and heat treatment.

\section{ACKNOWLEDGMENTS}

This work was supported (in part) by Ministry of Knowledge Economy (MKE) through the Center for Traditional Microorganism Resources (TMR) at Keimyung University, and supported by the Ministry of Commerce, Industry and Energy (MOCIE) and Korea Industrial Technology Foundation (KOTEF) through the Human Resource Training Project for Regional Innovation

\section{REFERENCES}

1. Shih IL, Van YT. 2001. The production of poly $(\gamma$-glutamic acid) from microorganisms and its various applications. Bioresour Technol 79: 207-225.

2. Thorne CB, Gómez CG, Noyes HE, Husewright RD. 1954. Production of glutamyl polypeptide by Bacillus subtilis. J Bacteriol 68: 307-315.

3. Troy FA. 1973. Chemistry and biosynthesis of poly $(\gamma$-glutamyl) capsule in Bacillus licheniformis: properties of the membrane-mediated biosynthetic reaction. $J$ Biol Chem 248: 305-315.

4. Liang HF, Yand TF, Huang CT, Chen MC, Sung HW. 2005. Preparation of nanoparticles composed of $\operatorname{poly}(\gamma$ -glutamic acid)-poly(lactide) block copolymers and evaluations of their uptake by HepG2 cells. J Control Release 105: 213-225.

5. Richard A, Margaritis A. 2001. Poly(glutamic acid) for biomedical applications. Crit Rev Biotechnol 21: 219-232.

6. Otani Y, Tabata Y, Ikada Y. 1996. Rapidly curable biological glue composed of gelatin and poly(l-glutamic acid). Biomaterials 17: 1387-1391.

7. Sekine T, Nakamura T, Shimizu Y, Ueda H, Matsumoto K, Takimoto Y, Kiyotani T. 2000. A new type of surgical adhesive made from porcine collagen and polyglutamic acid. J Biomed Mater Res 35: 305-310.

8. Borbély M, Nagasaki Y, Borbely J, Fan K, Bhogle A, Sevoian M. 1994. Biosynthesis and chemical modification of poly( $\gamma$-glutamic acid). Polym Bull 32: 127-132.

9. Park YJ, Liang J, Yang Z, Yang VC. 2001. Controlled release of clot-dissolving tissue-type plasmmogen activator from a poly(L-glutamic acid) semi-interpenetrating polymer network hydrogel. J Control Relese 74: 243-247.

10. Ashiuchi M, Kamei T, Baek DH, Shin SY, Sung MH, Soda K, Yagi T, Misono H. 2001. Isolation of Bacillus subtilis (chungkookjang), a poly- $\gamma$-glutamate producer with high genetic mompetence. Appl Microbiol Biotechnol 57: 764-769.

11. Inatsu Y, Kimura K, Itoh Y. 2002. Characterization of Bacillus subtilis strains isolated form fermented soybean foods in Southeast Asia: Comparison with B. subtilis (natto) starter strains. Jpn Agric Res Q 36: 169-175.

12. Oh SM, Jang EK, Seo JH, Ryu MJ, Lee SP. 2007. Characterization of the $\gamma$-polyglutamic acid produced from the solid-state fermentation of soybean milk cake using Bacillus sp. Food Sci Biotechnol 16: 509-514.

13. Akagi T, Kaneko T, Kida T, Akashi M. 2005. Preparation and characterization of biodegradable nanoparticles based on poly $(\gamma$-glutamic acid) with L-phenylalanine as a protein carrier. J Control Release 108: 226-236.

14. Ye H, Jin L, Hu R, Yi Z, Li J, Wu Y, Xi X, Wu Z. 2006. $\operatorname{Poly}(\gamma, \mathrm{L}$-glutamic acid)-cisplatin conjugate effectively inhibits human breast tumor xenografted in nude mice. Biomaterials 27: 5958-5965.

15. Seo JH, Lee SP. 2004. Optimization of the production of fibrinolytic enzyme from Bacillus firmus NA-1 in fermented soybeans. J Food Sci Nutr 9: 14-20.

16. Goto A, Kunioka M. 1992. Biosynthesis and hydrolysis of poly( $\gamma$-glutamic acid) from Bacillus subtilis IFO3335. Biosci Biotechnol Biochem 56: 1031-1035.

17. Thompson JD, Higgins DG, Gibson TJ, Clustal W. 1994. Improving the sensitivity of progressive multiple sequence alignment through sequence weighting, position-specific gap penalies and weight matrix choice. Nucleic Acids Res 22: 4673-4680.

18. Choi JI, Lee SY. 2004. High level production of supra molecular weight poly(3-hydroxybutyrate) by metabolically engineered Escherichia coli. Biotechnol Bioprocess Eng 9: 196-200.

19. Bradford MM. 1976. A rapid and sensitive method for the quantitation of microgram quantities of protein utilizing the principle of protein-dye binding. Anal Biochem 72: 248-254.

20. McNeil B, Harvey LM. 1993. Viscous fermentation products. Crit Rev Biotechnol 13: 275-304.

21. You S, Fiedorwicz M, Lim ST. 1999. Molecular characterization of wheat amylopectins by multiangle laser light scattering analysis. Cereal Chem 96: 116-121.

22. Hong X, Min J, Hui L, Dingqiang L, Pingkai O. 2005. Efficient production of poly $(\gamma$-glutamic acid) by newly isolated Bacillus subtilis NX-2. Proc Biochem 40: 519523.

23. Kelessidis VC, Maglione R. 2006. Modeling rhelogical behavior of bentonite suspensions as Casson and RobertsonStiff fluids using Newtonian and true shear rates in Couette viscometry. Powder Technol 168: 134-147.

24. Ito Y, Tanaka T, Ohmachi T, Asada Y. 1996. Glutamic acid independent production of poly $(\gamma$-glutamic acid) by Bacillus subtilis TAM-4. Biosci Biotechnol Biochem 60: 1239-1242.

25. Cromwick AM, Gross RA. 1995. Effect of manganese (II) on Bacillus lichniformis ATCC9945A physiology and $\gamma$ poly(glutamic acid) formation. Int J Biol Macromol 16: $265-275$ 
26. Leonard CG, Housewright RD, Throne CB. 1958. Effect of some metallic ions on glutamyl polypeptide synthesis by Bacillus subtilis. J Bacteriol 76: 499-503.

27. Suzuki T, Tahara Y. 2003. Characterization of the Bacillus subtilis ywtD gene, whose product is involved in $\gamma$-polyglutamic acid degradation. J Bacteriol 185: 2379-2382.

28. Kubota H, Matsunobu T, Uotani K, Takebe H, Satoh A, Tanaka T, Taniguchi M. 1993. Production of poly $(\gamma$-glutamic acid) by Bacillus subtilis F-2-01. Biosci Biotechnol Biochem 57: 1212-1213.

29. Kunioka M, Goto A. 1994. Biosynthesis of poly( $\gamma$-glutamic acid) from l-glutamic acid, citric acid, and ammonium sulfate in Bacillus subtilis IFO 3335. Appl Microbiol
Biotechnol 40: 867-872.

30. Kunioka M, Furusawa K. 1997. Poly $(\gamma$-glutamic acid) hydrogel prepared form microbial poly $(\gamma$-glutamic acid) and alkane diamine with water-soluble carbodiimide. J Appl Polym Sci 65: 1889-1893.

31. Scolnik Y, Portnaya I, Cogan U, Tal S, Haimovitz R, Fridkin M, Elitzur AC, Deamer DW, Shinitzky M. 2006. Subtle differences in structural transitions between poly-1and poly-d-amino acids of equal length in water. Phys Chem Chem Phys 8: 333-339.

32. Zanuy D, Aleman C, Munoz-Guerra S. 1998. On the helical conformation of un-ionized poly( $\gamma$-D-glutamic acid). Int J Biol Macromol 23: 175-184.

(Received July 22, 2008; Accepted November 14, 2008) 